\title{
BIM Quality Control Based on Requirement Linked Data
}

\begin{abstract}
This article discusses a BIM Quality Control Ecosystem that is based on Requirement Linked Data in order to create a framework where automated BIM compliance checking methods can be widely used. The meaning of requirements is analyzed in a building project context as a basis for data flow analysis: what are the main types of requirements, how they are handled and what sources they originate from. A literature review has been conducted to find the present development directions in quality checking, besides a market research on present, already widely used solutions. With the conclusions of these research and modern data management theory, the principles of a holistic approach has been defined for quality checking in the Architecture, Engineering and Construction (AEC) industry. A comparative analysis has been made on current BIM compliance checking solutions according to our review principles. Based on current practice and ongoing research, a state-of-the-art BIM quality control ecosystem is proposed that is open, enables automation, promotes interoperability, and leaves the data governing responsibility at the sources of the requirements. In order to facilitate the flow of requirement and quality data, we propose a model for requirements as Linked Data and provide an example for quality checking using Shapes Constraint Language (SHACL). As a result, an opportunity is given for better quality and cheaper BIM design methods to be implemented in the industry.
\end{abstract}

\section{Keywords}

BIM, Requirement, Linked Data, Quality Control, Quality Assurance, Compliance check

\section{Introduction}

Nowadays there are so many requirements and regulations that buildings have to satisfy, that designing a building became an overwhelmingly complex process. In an average real-estate development project, there are 10-12 disciplines participating and it can easily go higher depending on the complexity of the building. The Whole Building Design Guide ${ }^{1}$ lists 30 different domains. Furthermore, regulations are getting more complex year by year and it is an obstructive factor for the design process, according to a research ${ }^{2}$ made by the authors, where 90 out of 120 architects were of this opinion.

Manually managing the Quality Control (QC) of the building, from the accessibility requirement of a handle to an acoustic requirement of a window takes an almost impossible amount of effort. According to McGraw-Hill Construction ${ }^{3}$, in 2007, nearly half of architects and owners spent more than 26 hours on code checking during a typical project - in some cases even more than 100 hours. Interviewing Hungarian actors, these numbers are still realistic under current Hungarian circumstances.

Consequently, there is a great need for automation tools that can support the QC process in the AEC industry. In the present practice, QC automation goes as far as three options: geometrical clash and simple rule checking, quantity checking according to the space program, object level data validation in spreadsheets. Although these methods are improving the quality of the building, there are several pain points that these are suffering from: isolated databases, black-box effect, difficult new rule implementation, limited by IFC structure, etc. The main problem is that there is not a holistic approach that enables finding the global quality optimum 
of the building, just the local ones. ${ }^{4}$ Moreover, the present methods are file based and what one wins on quality improvement, loses on administration and on file management efforts.

Therefore, a conceptual framework and optimized data flow is proposed as a solution to this whole problem. The solution builds upon the building evaluation method ${ }^{5}$ which is a rule-based aggregation method for BIM data. Additionally, a prototype called BIM Dashboard ${ }^{6}$ has been implemented, which calculates and visualizes the data according to our evaluation method. During their further research, authors concluded that a systematic approach with a system-wide formalized description is in need for QC processes, which is going to be covered in this paper.

\section{About Building Requirements and Compliance Checking}

\section{Definition of a requirement}

Regarding requirements, firstly, it is wise to understand the exact meaning of the word. According to etymonline ${ }^{7}$ the word "requirement" originates from the word "require", which comes from Old French "requerre" meaning seek, procure, beg, ask, demand which comes from Latin "requirere". The "re" means repeatedly and "quirere" means query. This is interesting, because it seems from the very early times when they used the word, it was a query or demand that occurred multiple times, which means from the beginning it is a great terrain for automation - of course the technology for such is just given in the latest times.

According to Cambridge Dictionary ${ }^{8}$, it means, "something that you must do, or something you need". In a design context Wikipedia, says the following: "...a requirement is a singular documented physical or functional need that a particular design, product or process aims to satisfy. It is commonly used in a formal sense in engineering design.... .9

Requirements may be categorized in three types: according to the subject of the requirement, according to the data format type of the requirement and according to the origin of the requirement. The subject of the requirement can refer to the building as a product or to the process of the design or construction. This paper only deals with requirements applying on the building as a product. Requirements targeting processes are out of our scope, whereas it is also a necessary part of a BIM workflow. If the future physical building is taken as a product, the requirements can be interpreted on several levels. It can refer to the building as a whole, it can refer to a concrete structure or element of the building, it can refer to a structural connection or to a material. Every discipline has their own more or less different domain with their different subjects of requirements. It is an important task to consider all of these, if a universal logical model for requirements is desired. According to the description type of the requirement data, it can vary on a large scale. It can be plain text, a concrete value, table of values, calculation formulas, assessment systems, maps or any combination of the previously listed. In the next paragraph, examples which occur the most in architecture are going to be listed. According to the origin of a requirement, it can be anyone from the direct or indirect project participants: clients, regulators, designers and discipline designers, constructors, facility managers, etc. Distinguishing the origin of requirements is favourable because their frequency of data delivery, their data format of delivery, their data reliability and their data updating habits can differ, which all has an impact on the quality checking process. 
In the software industry the following characteristics are generally acknowledged regarding good requirements: unitary, complete, consistent, atomic, traceable, current, unambiguous, prioritized, verifiable. ${ }^{10}$ The AEC industry is a sector with a lot of traditions, hence it does not entirely fit the characteristics of the above listed, whereas it should be a goal to accomplish these characteristics in the future, which needs effort from all project stakeholders including authorities and clients as well.

\section{Data Analysis on the Main Type of Requirements Used in Architecture}

Originating from the client, the brief is the document that sets the project goals, constraints, requirements and initiates the building project. As Koutamanis ${ }^{4}$ brings up, a brief is actually an information system, a complex database that has many tables of information that are connected to each other. These tables basically connect requirements to elements and vice versa. Most of the following examples can be part of a brief, while some of them are engaged by only the designers.

Building or space program: Narrowly speaking, it is a list of all the required spaces with area requirements attached to it. There is not a standard format for it. Its data format is a table, which depending on the creator of the brief can contain additional requirements and constraints, for example: "Space type, Room name, Area, Height, Occupants, Proximity, Design comment"

Functional requirements: In the functional requirements the client gives information of the purpose of the given premise. It articulates who is going to use the room, how are they going to use it, what special activities they are going to do. Its data format is usually text, for example: "The office room should suit the needs of four architects, who work 8 hours a day behind high quality workstations, with screens."

Financial requirements: Financial requirements can be interpreted on project level, building level, or element level. The data format can be text, table or value. For example, "the pay-off rate of the project has to be $4 \%$ in ten years" or "the total cost of the building cannot exceed 100 million euros" or "the money spent on groundwork cannot exceed the $15 \%$ of the entire building."

Aesthetical requirements: The aesthetical requirements regarding for instance, style, shape or colours are subjective requirements. Therefore, the data format is always text. For examples: "the building should be futuristic", "the building should have playful colours", "the shape of the building should suggest a sailing ship".

Building performance requirements: There can be a great deal of discipline requirements concerning building performance. These requirements may origin from regulations or from professional standards, rules of thumbs and additional needs. The subjects of the requirements can also vary from the whole building, through integrated structures, to elements or materials of the building. The data format can be text, table, value or calculation method. For example: "according to the Hungarian 7/2006. (V.24.) TNM Energy Code of Hungary the U-value of the roof has to be min. 0,17 W/m² K", "according to the Hungarian 54/2014 (XII.5.) BM regulation about the National Fire Protection, the escape doors have to have a 60-minute fire protection value"

Building code and regulations: Building codes are specifying the degree of freedom concerning the geometry of the building, while local regulation maps are separating functional zones in the city, showing what functions are restricted in the given area and what types are 
free to build. The data format is usually text and maps. For examples: Hungarian Country-wide Urban and Building Requirements (OTEK), Local Urban Regulations.

Complete discipline assessment: There are disciplines which give a complete methodology to evaluate the building. For instance, LEED or BREEAM certification lines up several complex requirements from environmental aspects against the building. There are several subtopics where the building is being assessed and the sum result is a point, which in a certification range means a category. For example: basic, silver, gold, or platinum category. Accordingly, the data format of such a requirement is a methodology description in text format and the process has several calculations and data verification steps, sometimes supported by digital tools. ${ }^{11}$

Thus, these are the types of requirements that need to be checked during the QC process, in an ideal world, in a fully automated manner. There are many terms used in literature for this action: compliance checking, code compliance checking, clash detection, rule checking, model checking, validation checking, BIM-checking, quality checking and many more. ${ }^{12}$ In this paper, "BIM compliance checking" and "BIM quality checking" are used in synonyms, for naming the BIM based automated quality checking process.

\section{Theories and Tools for Compliance Checking in a BIM Environment}

A research has been conducted by the authors to see how developed the BIM compliance checking methods are currently. From the academic side, a literature review has been made to see the state-of-the-art theories and solutions developed by researchers. From the practical side, a market research has been made to see what tools are available currently for this purpose and what their exact value proposition and functional repertoire are.

\section{The four steps of BIM compliance checking}

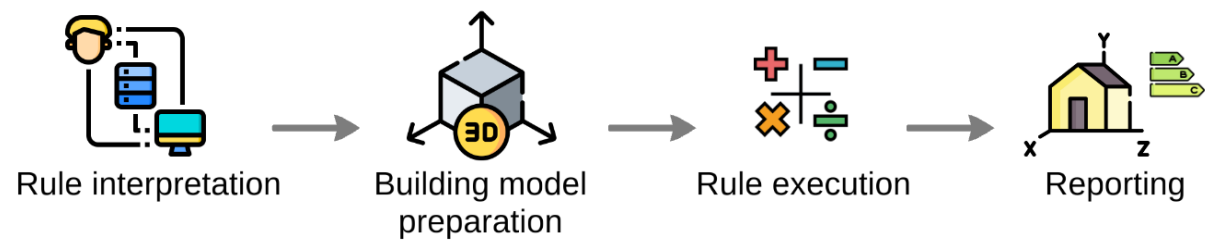

Figure 1. - The four major steps of the compliance checking process based on Ismail et al. ${ }^{13}$ Icons by flaticon. ${ }^{14}$

A compliance checking process has four major steps. ${ }^{13}$ (Figure 1.) The first is "rule interpretation". There are several approaches to translate and formalize the requirements written in natural languages for a compliance checking system: software approach (i.e.: Solibri, Navisworks), object-based approach (i.e.: CORENET e-PlanCheck), logical approach (i.e.: if-then validation, decision table methodology), ontological approach (i.e.: RASE, SBVR methodologies) The second step is the "building model preparation". A BIM model must be built in a way that it enables quality checking. It is important that the structure of the model and the information richness needs to conform with the given quality checking method. The third is "rule execution" 
or in other words, requirement conflict detection. This is the process when an algorithm compares the designed values to the requirements and creates a pass or fail tag according to the result. The fourth is "reporting" the result, when the results of the previous step are communicated to someone. This can mean a 3D visualization on the screen or a table with the conflicts each line. The purpose of this stage is to give a solid ground for designers to solve these issues. Such a report helps humans understand, follow and solve these problems effectively.

In this article the rule interpretation and the building model preparation steps are not going to be further discussed. It is assumed that requirements can be formalized to a certain extent. During our literature review several articles, that confirm this assumption, have been found. According to Eastman and Solihin ${ }^{15}$, as experienced in the FORNEX e-Plancheck project, the interpretation step can take as much as $30 \%$ of the total time of the whole process. The effort spent on rule interpretation depends mostly on the complexity of the rule. There are examples for compliance checking where the interpretation worked in different domains well: fire safety, acoustics, sustainability, construction, etc. Koutamanis ${ }^{4}$ analysed 10 building briefs and found that only $0-22 \%$ of the requirements were not supported in a BIM environment for QC theoretically. In another case, Bouzidi et al. ${ }^{16}$ formalized French Technical Guides to SPARQL language, where they were unable to implement $70 \%$ of the rules. Apparently, the solutions and the effectiveness of the interpretation methods vary on a great scale, but it works and automated compliance checking to any extent saves time for the designers and saves money for the client.

\section{The four types of BIM compliance checking}
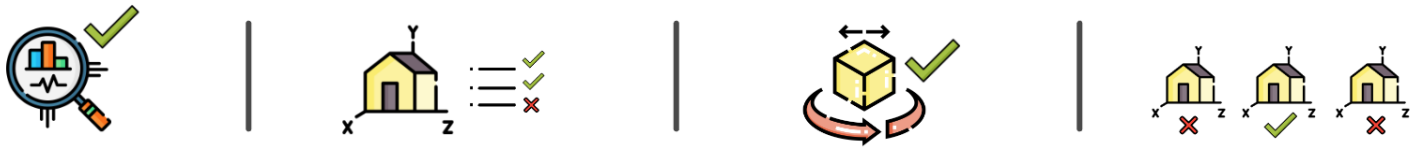

Validation checking Model content checking

Smart object checking

Design option checking

Figure 2. - The four types of BIM compliance checking according to Hjelseth ${ }^{12}$.

Icons by flaticon. ${ }^{14}$

According to Hjelseth, there are four types of BIM model checking ${ }^{12}$. (Figure 2.) The first is validation checking or in other words conflict detection. Clash detection is the most common example of validation checking, while code checking is an example of a popular type of checking, but with limited implementation. The validation checking can be based on multiple sources like codes, standards, contracts, best practice, or by other defined requirements. The second is model content checking, which aims to control the information richness of the model. According to an etalon list it states if all the necessary information is in the model or if there is extra unnecessary information which slows down the process. The third is smart object checking. This is not a posterior checking but a real time adaptive one. A parameter of a given object can be linked to another object's parameter so when it changes, it automatically refreshes the connected parameter and adapts to the new state. According to our interpretation this type of checking could be possibly a subdivision of the validation checking type. The fourth is design option checking. This means that the BIM model is being confronted to a complex 
knowledge base and alternative design versions are given according to the conclusions. These types of solutions are at a very immature level in the AEC industry.

\section{Present Solutions and Tools}

The first group of tools that enable automated compliance checking to a certain extent are the briefing, specification and project database software tools. A benchmark ${ }^{17}$ has been conducted in late 2019 with briefing software products ${ }^{18-20}$ (MasterSpec, Bsdspeclink, dRofus) used in practice. After learning about the capabilities of the software products listed, it seems the market has changed since 2017 and the software is more developed, but the statement is still valid from Koutamanis: "Existing tools are less than generous with their connections to BIM. Most preserve their standalone character, merely allowing content to be imported or linked to BIM. Their information generally remains locked in databases hidden in proprietary software, often replicating data that exist in a model and impeding connections between different kinds of information.". ${ }^{4}$

The second group of such solutions are executed by CAAD and BIM programs (e.g.: Revit21, Archicad ${ }^{22}$ ) with extended plugins, scripting or in combination with Excel. Most of the case studies reported about using Revit plugins for a given discipline requirement checking, for example for fire protection rule checking ${ }^{23,24}$. There are also scripts that generate a TRUE or FALSE value in the BIM software if a certain parameter of an object complies with a requirement value. The simpler version of this solution is when the objects with their parameters are exported to a table and the comparison resulting TRUE or FALSE value is generated in Excel. These solutions are working only with those discipline requirements where the nature of the rules is mostly simple data validation and the rule diversity is low.

The third group of programs are the model checkers. The ones that are mostly used in practice are from the big software vendors ${ }^{25,26}$ (Solibri, Navisworks), but there are also emerging cloud based solutions ${ }^{27-31}$. These solutions provide automated analysis and checking regarding design issues, detecting design deficiencies, and checking the model against rulesets, for example accessibility, fire protection, etc. Mostly they implement hard-coded functions, therefore the end-user cannot find out how the rules exactly work. It is argued that adding new rules is a difficult task as it can only be custom made by the software developers ${ }^{32}$.

In the fourth group, there are research projects with different experimental methods for compliance checking. Most of them are based on the open standard file formats and data schemes governed by buildingSMART ${ }^{33}$, such as IFC, BCF and mvdXML. During our scientific review only one freely accessible workflow, called IFCdoc-mvdChecker workflow ${ }^{34}$ has been found, with open source or free software and usable documentation. It is going to be introduced in detail in the next section, but the conclusion was that there are two major issues with it. One comes from the limitation of the IFC: limited expression range, difficulties in partitioning the information, multiple description possibilities for the same information ${ }^{35}$, rigorous flexibility, not tailored for query and analysis tasks. ${ }^{36}$ The other is the User Interface (UI), which is not designer friendly.

As a matter of experimental methods, there are two main directions: using Structured Query Language (SQL) $)^{13,37-39}$ or Semantic Query Languages ${ }^{40}$. There are advances in both directions, but it looks like the semantic approach is the more forward-looking one. The use of Shapes Constraint Language (SHACL) is suggested by the authors and other researchers as well. ${ }^{36,41}$ An example of using SHACL for compliance checking of a BIM database will be introduced later. 


\section{Suggested Principles of a BIM-based Compliance Checking}

On Table I., eight principles are proposed, based on the literature review and market research discussed above and modern data management theory regarding data openness and interoperability ${ }^{42}$, that should be satisfied by a state-of-the-art BIM compliance checking system.
I. Quality Control is expected to be software independent, interoperable and open source.
II. The method of requirement input should be automatized.
III. Possibility for conflict detection in requirement fulfillment.
IV. The result of the conflict detection should be visualizable in multiple ways.
V. The quality checking method should exceed the limitations of the IFC data structure.
VI. The requirements should support data linking and data interoperability.
VII. Contiguous data flow from the source of the requirements to the quality checking agent
VIII. Requirement data governance should be distributed at the responsible agents.

Table. I. - Suggested Principles of a BIM-based Compliance Checking

Principle I. Quality Control is to be software independent, interoperable and available as open source. Quality checking is a sensitive process because there are multiple parties included with great amounts of money, work and credibility at stake. Therefore, the whole process should be transparent and well understood by every project stakeholder. Hence these parties should use their own digital tools that they know well. Besides the whole requirement information package should stay independent from the stakeholders, consequently the quality checking information should be handled separately from the model, in an open-source way that is supported by existing BIM software. ${ }^{12}$ The possibility for localization is also an important issue, as it will facilitate the use of open-source digital quality control methods in smaller languages. ${ }^{32}$

Principle II. The method of requirement input should be automatized. If a great amount of work is saved on using automated model checking methods, it should not be given away by spending more time on administration of the requirement parameters. Hence, there should be a way to auto-populate the object parameters with the required values, that will just satisfy the criteria. ${ }^{43}$

Principle III. Possibility for conflict detection in requirement fulfilment. The quality checking method should enable conflict detection, including geometrical clash detection and attribute information discrepancy detection. As a result, a pass-or-fail label should be generated. ${ }^{12,44}$

Principle IV. The result of the conflict detection should be visualizable in multiple ways. The results of a conflict detection should be easy to understand for most of the project participants, therefore multiple visualization methods should be used: 3D data visualization on the BIM model, 2D diagrams, tables and graphs. ${ }^{6,45,46}$

Principle V. The quality checking method should exceed the limitations of the IFC data structure. As previously mentioned, the IFC data model is not flexible enough, because it is not 
designed for various query and analysis tasks. Furthermore, much information used in common industry scenarios is not specified within the scope of the IFC data model. ${ }^{36}$

Principle VI. The requirements should support data linking and data interoperability. The practical reason for this point is that the whole QC process should be trustworthy and transparent to every project participant. The theoretical reason is to minimize the necessary data translations between tools, which is one of the basic principles in data interoperability. The Linked Data approach ensures the connectivity of data at various servers and helps to avoid file downloads as a primary mean for data exchange. ${ }^{36,47}$

Principle VII. Contiguous data flow is expected from the source of the requirements to the quality checking agent. Linking requirement data is a requisite, but not a sufficient premise. It is also important that this data linking is contiguous from the source of the given requirement to the software which executes the conflict detection. ${ }^{41}$

Principle VIII. Requirement data governance should be distributed at the responsible agents. Keeping the requirement data up-to-date, giving continuous accessibility to it, sending notification when changes occur and holding legal responsibility for it should belong to the given requirement data responsible agents. ${ }^{4,32,48}$

\section{Fulfilment of Suggested Principles on Existing Solutions}

The main goal was to look at the big picture of the above discussed solution repertoire in a comparable manner to see the fulfilment of our suggested principles. Therefore, a comparative analysis has been made on Table II. Only the results of each solution category are listed, where the software products and services are summed that were mentioned under "Present Solutions and Tools". 3 types of markers were used: yes, no, and partly. Yes, means all of the solutions in that category is according to the given principle, while no means the opposite. Partly means there are solutions that more or less satisfy the given principle.

\begin{tabular}{|c|c|c|c|c|c|c|c|c|}
\hline & $\begin{array}{c}\text { I. } \\
\text { Software } \\
\text { independent, } \\
\text { open source }\end{array}$ & $\begin{array}{c}\text { II. } \\
\text { Automatized } \\
\text { requirement } \\
\text { input }\end{array}$ & $\begin{array}{c}\text { III. } \\
\text { Conflict } \\
\text { detection }\end{array}$ & $\begin{array}{c}\text { IV. } \\
\text { Multiple } \\
\text { visualization } \\
\text { methods } \\
\end{array}$ & $\begin{array}{c}\text { V. } \\
\text { Exceed IFC } \\
\text { limitation }\end{array}$ & $\begin{array}{c}\text { VI. } \\
\text { Support data } \\
\text { linking and } \\
\text { interoperability }\end{array}$ & $\begin{array}{l}\text { VII. } \\
\text { Contiguous } \\
\text { data flow from } \\
\text { source to agent }\end{array}$ & $\begin{array}{l}\text { VIII. } \\
\text { Distributed } \\
\text { requirement } \\
\text { governance }\end{array}$ \\
\hline $\begin{array}{r}\text { Briefing Softwares } \\
16-19\end{array}$ & no & yes & partly & partly & yes & no & partly & no \\
\hline $\begin{array}{r}\text { CAAD and BIM software solutions } \\
61-62\end{array}$ & partly & no & partly & yes & yes & no & no & no \\
\hline $\begin{array}{r}\text { Model Checkers } \\
22-28\end{array}$ & no & no & yes & yes & partly & no & partly & no \\
\hline IFCdoc, mvdChecker Workflow & yes & no & yes & partly & no & no & no & no \\
\hline $\begin{array}{r}\text { Experimental Research Projects } \\
13,34-36\end{array}$ & yes & partly & yes & partly & yes & yes & partly & no \\
\hline $\begin{array}{r}\text { BuildingSMART file formats } \\
30\end{array}$ & yes & partly & yes & partly & no & no & no & no \\
\hline
\end{tabular}

Table II. Comparative analysis on available quality checking solutions by category

Firstly, there is no solution which satisfies all principles. Secondly, it is apparent that the last three are the main bottlenecks, meaning there is not yet a widely recognised solution based on Linked Data. Also automatized parameter input is only figured out in the minor of the solutions. On the other hand, conflict detection is doable in most cases and there are open-source 
solutions which are only in the seed phase but started to evolve in a good direction. The same is valid for the visualization methods. There are some promising dashboards and visualization methods for the QC results, but designer friendly and efficient solutions are still awaiting.

To sum up, there is no BIM based QC solution that satisfies our principles and is accessible for offices in a usable and affordable way. Although the quality of basic geometrical and attribute information export has improved and some BIM products started Application Programming Interface (API) data exchange services, there is still no standard for requirement data exchange which could allow the integration of the already existing BIM tools. There is stateof-the-art research tackling this topic and testing prototypes but there is a great need for BuildingSMART, as the leading party in open file formats concerning the AEC industry, to make advancements regarding this topic. In the following, the currently available state-of-the-art QC workflow has been investigated, where the above-mentioned solutions are used.

\section{Open BIM Based Quality Control Solutions in Context}

\section{State-of-the-art Open BIM Based Quality Control}

The state-of-the-art open BIM QC workflow is shown on Figure 3. based on the literature review and the market research discussed earlier. Only those QC solutions have been put on the workflow diagram, that are thought to be of a consensus in the literature and which have usable and accessible solution for a given function. There are two types of blocks. One is the source of requirements, who are the responsible agents, namely the client, the authorities, and the designers - shown by icons - and the other is the QC solution block. In the following, these blocks are explained one by one.

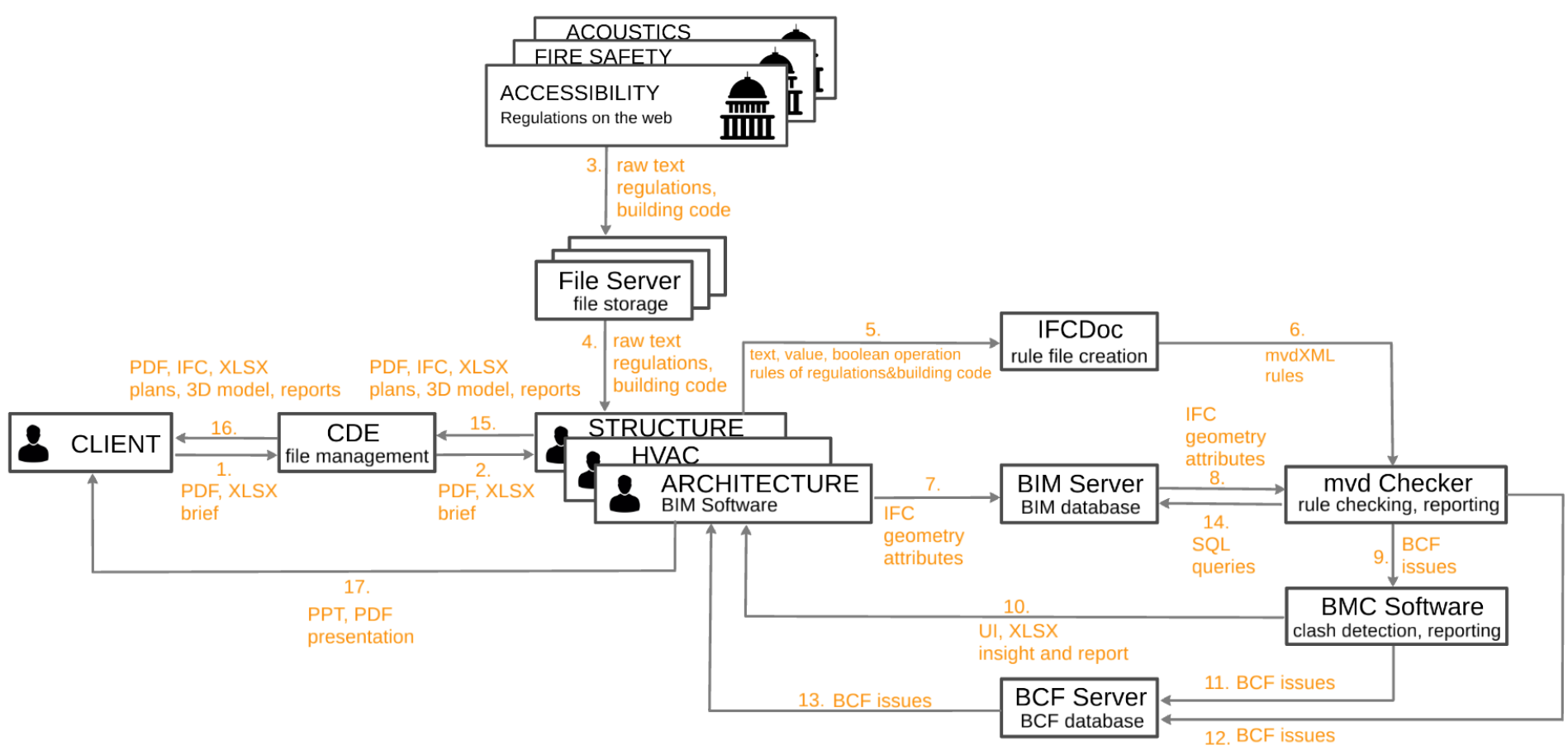


Figure 3. State-of-the-art Open BIM Based Quality Control

\section{Blocks of the State-of-the-art Quality Control}

CDE (Common Data Environment): The ISO $19650^{49}$ standard defines the CDE as a common platform for project participants to share and store project deliverables. There are a great variety of solutions on the market regarding functionality. Starting from the most basic ones, which are basic file servers to the more advanced ones, which are implementing even some quality control services as well. Since this QC process is based on file sharing, on this diagram it is represented as an advanced file management server, meaning multiple criteria can be set, for example, what kind of files and in what interval can be uploaded. As a result, the file exchange can be managed and documented for the QC process. Project managers are capable of checking if the deliverables were finished in time or the naming convention was according to the project nomenclature. The cash flow of the project depends on the deliveries, therefore it is important to quality check this process. A CDE is substantial from the building's performance aspect too, because the requirements from the client are uploaded here in a form of a brief and the designers will be able to access it via the CDE. The type of files stored here from the client are typically documents like PDFs, XLSXs and from the designer side, are PDFs, XLSXs, IFCs or native BIM model files.

File server: The file server is the designers' file storage, where they store all data received or researched related to the building project. This is the place where they store a copy of the incoming point clouds, 3D models, site photos, etc. Besides it is also the place where they download the current regulations, building codes and other professional requirements. The type of the requirement data stored here is usually raw text from an HTML site, from a PDF, or sometimes from a spreadsheet or even from a map with the local building code.

BIM server: The BIM Server ${ }^{50}$ is a database for the BIM model. The model is imported as an IFC file and all the BIM information, meaning both geometrical and attribute data, reside in an SQL database, which can be queried for various QC reasons.

IFCDoc: IFCDoc ${ }^{51}$ is a software tool for rule creation. When designers decode the regulations into several rules, this is the tool where they can formalize them and connect them to IFC attributes, so the rule checking can be done automatically. The output is an mvdXML file containing the given ruleset.

mvdChecker: The mvdChecker ${ }^{52}$ is a software that performs rule-checking algorithms, that makes the information conflict detection between the requirement value and the designed performance value. As input, it imports the ruleset to be validated from the mvdXML file and the BIM model through querying the BIM server. As a result, issues are generated for each conflict and exported as a BCF file.

BMC software: A BIM-based Model Checker ${ }^{12}(B M C)$ can perform conflict detection algorithms. There are well-known BMC tools mentioned earlier, but additionally mvdChecker is actually a $\mathrm{BMC}$ software too. The first reason for having two software components with the same function in this process is because Solibri, as the second BMC software, is able to visualize the conflicts 
on the 3D model with free software versions, whereas mvdChecker does not have a 3D window. The second reason is because the mvdChecker is not meant for geometrical clash detection, whereas Solibri's or Navisworks' main feature is just that. So, with this block, designers can on one side, further explore geometrical anomalies through the BMC's $\mathrm{UI}$ and on the other side, explore the issues in 3D space which were generated by the mvdChecker. As a result, designers gain better understanding of the problems, and can export the newly found issues to the BCF server.

BCF Server: The BCF server ${ }^{53}$ imports all the design issues in the form of BCF files, both from the automatic QC process and both from the manually entered issues from other designers. All entries are merged into one issue database, which then can be queried by the designer parties into their own BIM software via plugin or via BCF file exchange.

\section{Summary of the State-of-the-art Solutions}

Overall, this workflow is still mainly file based, although these are open standard formats such as IFC, BCF, mvdXML. It enables BIM model-based QC, but it requires IT experts as well, who can see through the software environment and are familiar with the above-mentioned open file formats. It concentrates only on the part of the design process that is beyond the designers and does not provide a framework for handling requirements throughout the whole process. Finally, as shown on Table II. at the "IFCdoc, mvdChecker Workflow" line, this QC workflow does not meet principles $\mathrm{V}$.-VIII. and only partly capable of automation.

\section{Suggested Open BIM based Quality Control Ecosystem}

Most research regarding this topic focuses only on a few aspects of the BIM QC workflow, for example on regulation to rule conversion methods, analysing and testing new technologies or creating new pieces of software. Even if their research scope involves the context, usually their solution deals with only a certain discipline requirement type of the QC problem. For example, fire safety, with only the related software and user environment. Therefore, from the industry point of view, these are partial successes, but from a universal BIM QC point of view, these approaches are not wide enough. Hence the concept "BIM Quality Control Ecosystem" has been introduced, which deals with the QC solutions, the involved parties, and their relation to the whole process at the same time.

An ecosystem is suggested on Figure 4., that corresponds to our previously stated principles. As a result, the QC process will be of better quality, with less administrative workload on the project participants, enabling BIM design methods to become cheaper and more widespread.

In accordance with the above, our ecosystem is a modular and open system, where BIM functions are separate entities. This way any module is replaceable and the software in use can be freely chosen.

Every party who establishes requirements are responsible for them and they must govern them throughout the project. Moreover, there is a Linked Data connection between these parties' requirements all the way to the quality checking tool. This means a lot of administrative redundancies and extra human-to-human communication can be saved, while the chance of making mistakes is reduced. 


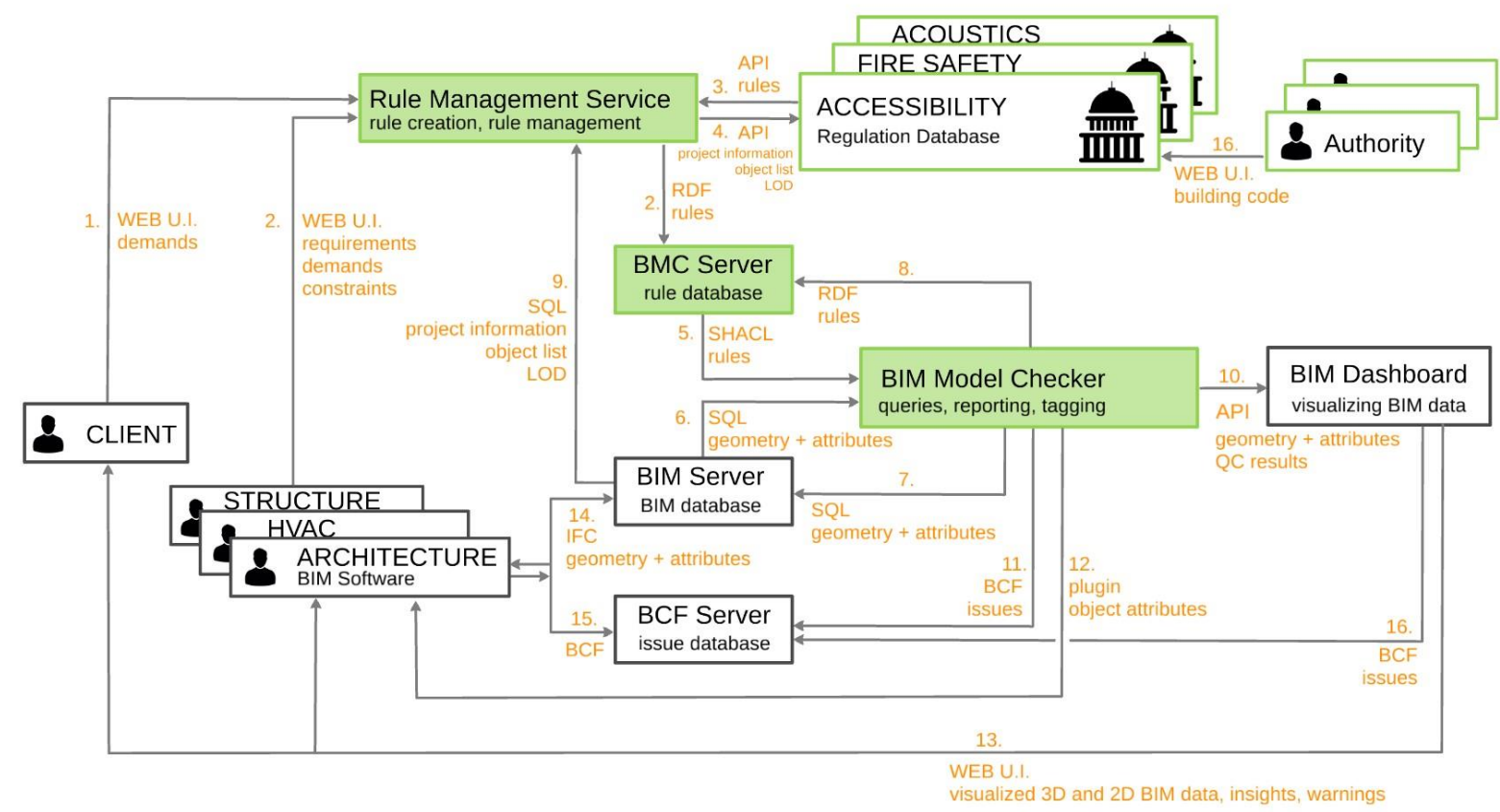

Figure 4. Suggested Open BIM based Quality Control Ecosystem

The ecosystem relies on three databases: the first is the BMC server, where all the quality checking rules from all different sources are collected. The second database is the BIM server where the design models are stored. The third one is the BCF server where the issues concerning the design process are stored. One can input data into these databases and can query these databases with a suitable software tool. While all these databases should avoid redundancy, should be based on linked data and should track changes, this paper only focuses on the BMC server and the requirement information in our conceptual example. Regarding the other two databases, it is desirable to build upon tools which are already used and can be adapted to the ecosystem while corresponding to our principles. That is why the BIM server ${ }^{50}$ and the BCF Server ${ }^{53}$ have been applied. It was also desirable to enable Transparent Design ${ }^{54}$, which means any requirement conflicts can be traced back to their sources at any given point of the design process.

\section{Modules of the Suggested Ecosystem}

4 types of modules have been differentiated: data generation, data storage, automatic quality checking and BIM data visualization tools. According to our findings these should be separate entities. The main concept is that the data generation modules such as the Rule Management Service and BIM Software are sending the generated data to independent project databases. The rule checking software accesses these databases and executes the rule checking algorithm. The results of rule checking can then be sent for further processing, to the BIM dashboard, the BCF server or the BIM software.

There are three main advantages of this modular concept. The first is that there is no need for one complex software that handles every task, as it threatens the users with vendor lock-in, expensive customizations or a steep learning curve. The second advantage is that any custom software can be used which fits the purpose of the given module. For example, any kind of BIM software that fits the designers' needs or any kind of data server, no matter if it is located in the cloud or it is a local one, works within the system. Furthermore, any kind of rule checking or 
dashboard software that is trusted by the project participants or suits the client's need can be used. The third benefit is that the modules and data connections among them can be upgraded separately. Consequently, upgrading can be done one by one, and does not have to change the whole ecosystem simultaneously. The explanation of the modules is the following.

Regulation Database: Every authority should have their own regulation database. The authority personnel convert the regulations to machine-readable rules within their Rule Management Service. There are already existing methods for such conversions mentioned earlier. Based on the literature review it seems the RASE methodology is the most widely used one. ${ }^{55,56}$

Once the rules are added to the regulation database, they are searchable through the web. In every building project, designers should download the rules that are relevant for their exact project to the project rule database on their BMC server. As a result, all the requirements to be fulfilled from the authorities are in one place and are trackable back to its source.

The idea of the regulation database conforms to the theory of distributed building data. ${ }^{41}$ Werbrouck et al. even tested a technical solution in this topic which looks promising. They used the Solid ecosystem ${ }^{57}$ to make connections with proper authentication between the distributed building project data. After building up the connection they used SHACL to collect the proper data they wanted. The same process could work in our case as well. The authorities and the BMC server would be the points to be connected through Solid, and the requirement data would be distributed among them.

Rule Management Service: Each project stakeholder who establishes requirements can feed these into the system through the $\mathrm{UI}$ of this data generation type of module. As a result, machine-readable rules are created that can be used in the automatic quality checking process later. A great benefit of this module is that if the rules are being digitized at their sources, then other stakeholders do not have to decode and re-encode them wasting resources, which would happen in a traditional workflow. Zahedi et al. created a prototype ${ }^{58}$ that possesses this functionality in their own system.

BIM software: Designers can create the geometry of the building and add extra information to it with this data generation type of module. There are several BIM software products used in the projects depending on the given discipline.

BMC server: BIM Model Checker server is a database for all the rules that needs to be satisfied during the design process. It is analogous to the BCF server since information is coming from several different sources and needs to be handled together. The BMC software will utilize this database to do the model validation based on Linked Data. The main advantage of this module is that it holds all requirements in one place, as a result, reducing redundancy, enabling traceability and transparency.

BCF server: This module provides storage and querying facilities for the design issues of the project, as discussed in the state-of-the-art QC workflow.

BIM server: It provides storage and querying facilities for the BIM model, as discussed in the state-of-the-art QC workflow. 
BIM Model Checker: The BIM Model Checker (BMC) is a software tool that runs automated quality checking algorithms. It can perform both the geometrical clash detection and the requirement conflict detection. There are several possible applications of this module. The first is to send the end results of the QC to the BIM Dashboard where it can be visualized as decisionsupport. The second is to generate issues and send them to the designers via the BCF server. The third is to send the end results to the designers' BIM software via a plugin.

BIM Dashboard: The BIM dashboard ${ }^{6}$ is a software tool to visualize building data with the results of the automated QC process in an efficient, and user-friendly way that a human eye can easily process. The data visualization should not just focus on the 3D geometry, but just as much on $2 \mathrm{D}$ diagram views. The concrete output is the visualized $3 \mathrm{D}$ and $2 \mathrm{D}$ BIM data, insights and warnings, which are accessible for all project stakeholders through a web UI as decisionsupport. Further issues that occur during the exploration of the BIM model through this module, can be sent to the BCF server. There are promising proof of concepts ${ }^{45,46}$ that are good candidates for this module.

\section{Summary of the Suggested Ecosystem}

This ecosystem is designed according to all our BIM-based Compliance Checking principles and tries to overcome the weaknesses of the existing solutions as presented. A critical factor of this conceptual framework is the interoperability of requirement information. Hence, authors propose a data structure for Requirement Linked Data.

\section{Proposed Data Model for Requirements}

Our suggestion is formalised as an ontology, since interoperability and self-description are core features of Linked Data, to be utilized here. The usage of Linked Data is growing significantly year by year. In the EU, Core vocabularies are promoted for describing Persons, Businesses, Locations, Criteria, etc. ${ }^{59}$ Further ontologies or RDF schemas are widely used for metadata provisioning (Dublin Core ${ }^{60}$ ), describing persons $\left(\mathrm{FOAF}^{61}\right)$, metrics and measurements (QUDT ${ }^{62}$ ), etc. In fact, BIM also follows these principles, though IFC is not defined primarily in RDF. For example, the BIM Ontology ${ }^{63}$ helps to structure semantically the terminology of buildings.

In 2018, the UN World Data Forum also voted for the linked-data approach in its guide for data governance ${ }^{64}$. Hence, the solution suggested here is the BIMReq ontology ${ }^{65}$ (Figure 5.), which enables rich semantic description of requirements, thus leverages intelligent management, reasoning and visual evaluation of building requirements. BIMReq offers descriptions for the following concepts: regulations, requirements and evaluations.

Regulations are described primarily with the metadata necessary for identification using Dublin Core terms. In this way the date, creator, name and identifier of the regulations can be provided by the regulator together with the link to the full regulatory text. Furthermore, subject classifications may be given by discipline type and regulated object type. Optionally, a full SHACL ${ }^{66}$ expression may be attached translating regulation text into compliance checking rules. Ideally, the Regulation Linked Data would be maintained and made accessible by the regulator. 


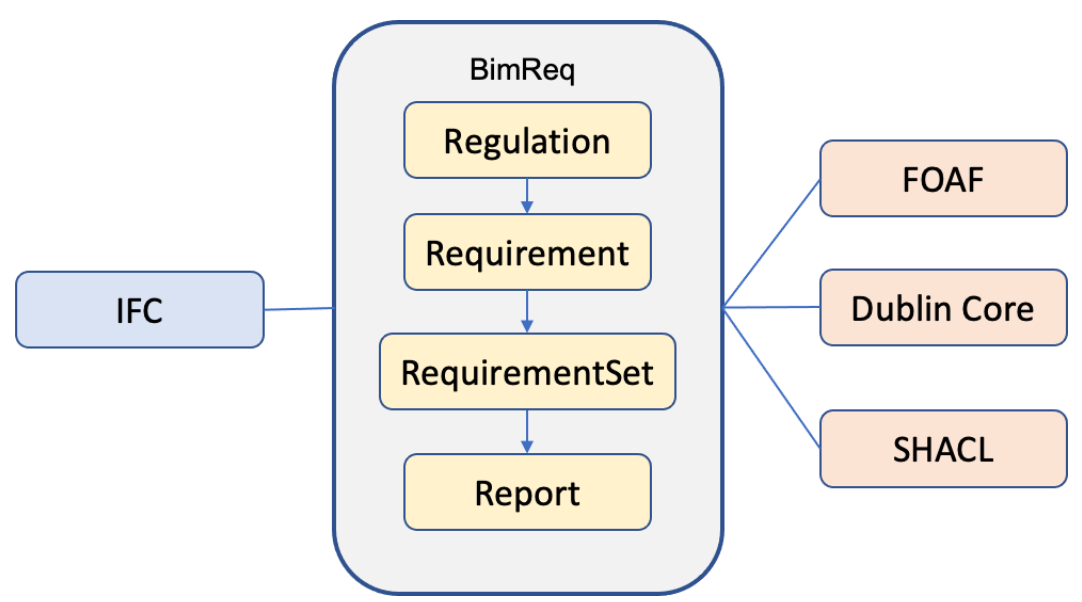

Figure 5. Key elements of the BIMReq ontology

The next key concept is requirement, which can be grouped into requirement sets and can be bound to construction projects and IFC models. Requirements may be raised by the client or a designer but may also be derived from regulations. In the latter case the requirement connects the regulation to selected parts of the IFC model and may also concretize the expected measurements. Requirements should also contain descriptive metadata, minimally the creator, creation date and short description. Subject categories can help filtering requirements by object type, object location or discipline type.

There are several possibilities for automated compliance checking, depending on the tools and formats used in the project. In case of IFC XML, Xpath expressions can be created, in case of plain IFC custom scripts may do the checking, while in case of IFC OWL one can use SHACL (an example is given later). From all these possibilities SHACL is the most promising, as it provides a full validation framework and the most readable format.

Requirements may be evaluated multiple times by multiple people. An evaluation contains the evaluator, the date and the result, which may be an objective result of a calculation or a subjective ranking or a pass-fail stamp. However, it is assumed that many of the requirements can be checked against the BIM model based on rules generated from the requirements.

As an example, a thermal transmittance requirement is defined on a window:

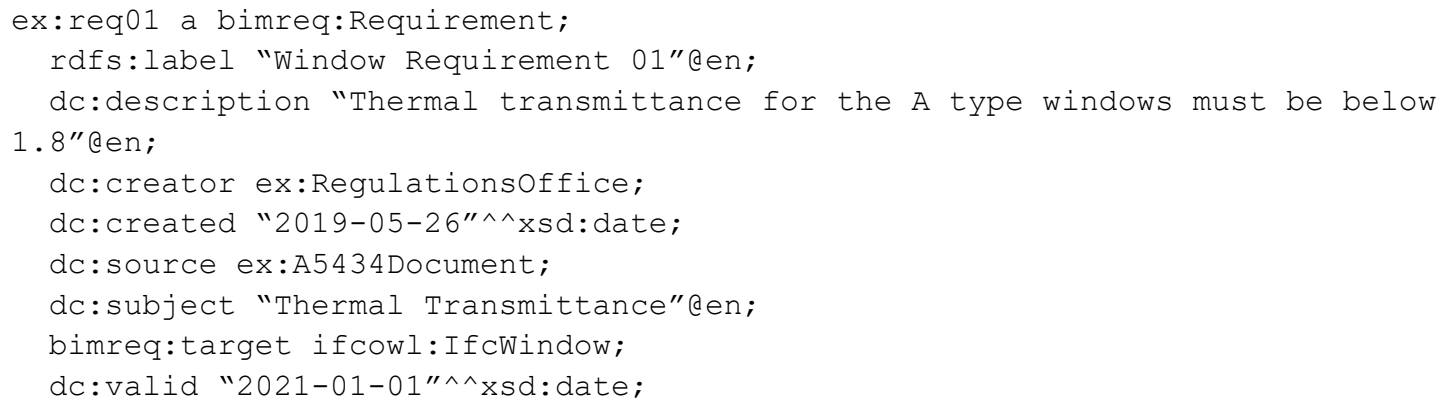


Based on this requirement, one can easily generate a BCF Comment to pass forward to BIM applications. Furthermore, one can use SHACL to auto-generate compliance reports for the BIM Model. The shape expression for the requirement above could look like the following:

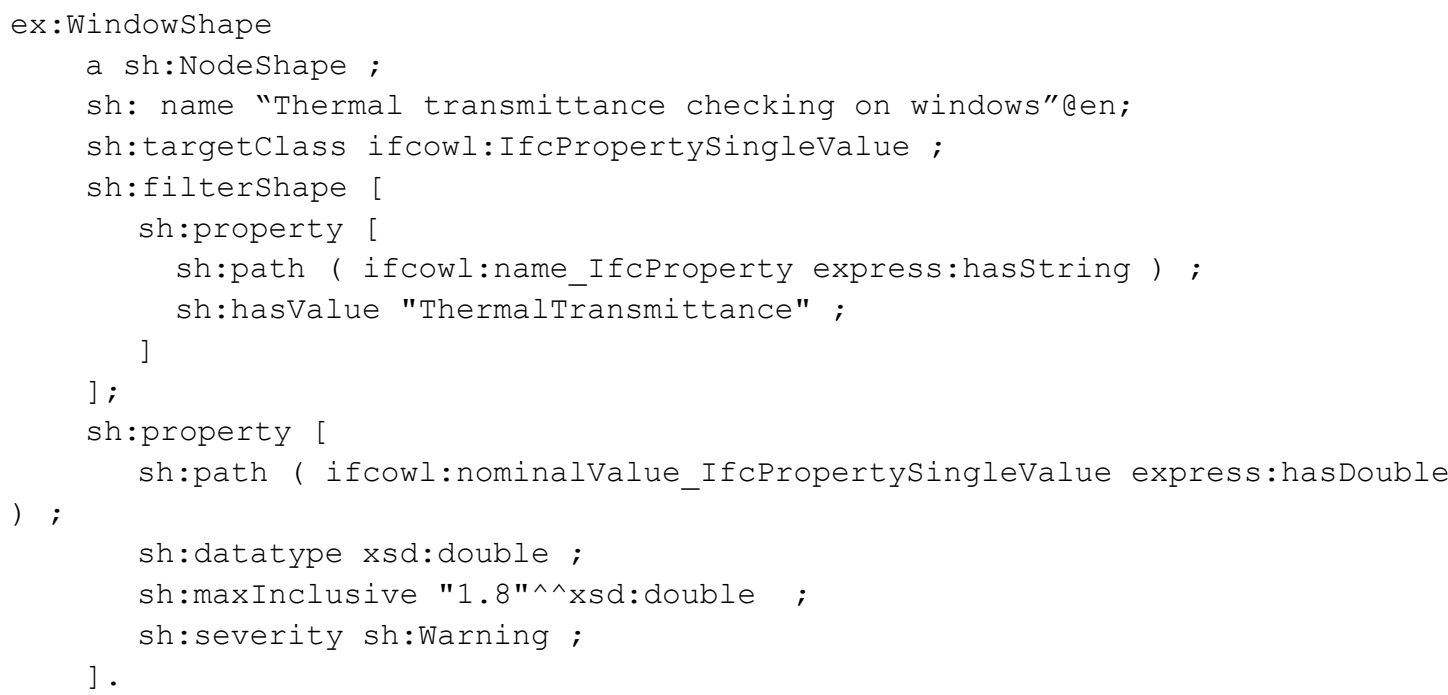

SHACL reports can then be transformed into plain text reports, BCF comments or spreadsheets, which can either be read by humans or imported into BIM tools for further processing.

\section{Conclusions and Future Research}

It has been discussed that there is a great need for improving the QC process of a building, since manually managing so many requirements is unfeasible and error-prone. After the current software products, workflows and experimental technologies have been analysed, authors articulated eight principles that are thought a state-of-the-art BIM based QC ecosystem should possess and a conceptual framework has been designed in compliance with these. A logical model has been proposed for the requirement data structure in Linked Data representation which can provide data interoperability for various software tools enabling a large variety of QC management solutions.

As a result, the whole QC process becomes transparent and more understandable for all stakeholders, causing less errors, less conflicts and less monotonic tasks. Authors suggest a proper distribution of requirement data governance in accordance with responsibilities. Authorities maintain a set of machine-readable regulations, which are easy to re-use in construction projects via Linked Data connection, while designers may compile and re-use requirement profiles for typical building projects. Finally, the file-based communication between the client and the designers has been shifted to information-based, using open and Linked Data formats.

New methods and tools were suggested, as modules of the proposed ecosystem, for automated checking of requirement fulfilment, reporting and visualization of quality checking results. A possible missing piece in the tool line is the software support for generating Requirement Linked Data. 
This ecosystem opens gates for new functionalities and new custom developed solutions. A promising direction in the future is extending the time frame of this ecosystem to the full lifecycle of the building. During the construction phase, product changes could be validated or in the operation phase manufacturers could be tendered automatically for refurbishment according to the given requirements, saving money for the investors and speeding up the process. Also, it would be interesting to see how this ecosystem could work with new distributed technologies such as the Solid Platform ${ }^{57}$ or Blockchain technologies ${ }^{67}$. Moving towards a datadriven design methodology, may trigger many exciting new developments in the next decades.

\section{References}

1. Whole Building Design Guide, https://www.wbdg.org/ (2020).

2. Kovacs AT. Az építészeti tervezés jövője Magyarországon az elkövetkezendő 20 évben. In: Nováky, Erzsébet; S. GA (ed) A múltból átívelő jövő: VIII. Magyar (Jubileumi) Jövőkutatási Konferencia : 50 éves a magyar jövőkutatás. Budapest: Palatia Nyomda és Kiadó Kft., pp. 329-339.

3. Mc Graw Hill. Construction, Interoperability in the Construction Industry, Smart Market Report. 2007.

4. Koutamanis A. Briefing and Building Information Modelling: Potential for integration. Int J Archit Comput 2017; 15: 119-133.

5. Kovacs AT, Micsik A. Method for Evaluating a Building Information Model. Period Polytech Civ Eng. Epub ahead of print 11 April 2019. DOI: 10.3311/PPci.12563.

6. Kovacs AT, Micsik A. Building Information Dashboard as Decision Support during Design Phase. In: Computing for a better tomorrow - Proceedings of the 36th eCAADe Conference. 2018, pp. 281-288.

7. Etymonline, https://www.etymonline.com/search?q=requirement (2020).

8. Cambridge Dictionary. https://dictionary.cambridge.org/dictionary/english/requirement.

9. Wikipedia. https://en.wikipedia.org/wiki/Requirement.

10. Alan M. D. Software Requirements: Objects, Functions, and States, Second Edition. Second Edition. Prentice Hall.

11. Arc Skoru. https://www.arcskoru.com/.

12. Hjelseth E. Classification of BIM-based Model Checking Concepts. J Inf Technol Constr 2016; 21: 354-369.

13. Ismail AS, Ali KN, lahad NA. A Review on BIM-Based Automated Code Compliance Checking System. In: IEEE TENSYMP 2017: IEEE International Symposium on Technologies for Smart Cities. Kochi, 2017.

14. Flaticon. https://www.flaticon.com/. 
15. Eastman CM, Solihin W. A Knowledge Representation Approach in BIM Rule Requirement Analysis Using the Conceptual Graph. J Inf Technol Constr 2016; 21: 371-401.

16. Bouzidi KR, Fies B, Faron-Zucker C, et al. Semantic Web Approach to Ease Regulation Compliance Checking in Construction Industry. Futur Internet 2012; 4: 830-851.

17. Choosing the Right Specification Software for an Architecture or Interiors Firm. https://archinect.com/features/article/150172257/choosing-the-right-specificationsoftware-for-an-architecture-or-interiors-firm.

18. MasterSpec. https://avitru.com/.

19. Bsdspeclink. https://bsdspeclink.com/.

20. dRofus. https://www.drofus.no/.

21. Autodesk Revit. https://www.autodesk.com/products/revit.

22. Graphisoft Archicad. https://graphisoft.com/solutions/products/archicad.

23. Shih S-Y. Challenges Associated with Implementing BIM-Enabled Code-Checking Systems within the Design Process. University of Newcastle, 2015.

24. T. H. N, J. L. K. Building code compliance checking using BIM technology. In: Winter Simulation Conference. 2011, pp. 3395-3400.

25. Solibri. https://www.solibri.com/.

26. Navisworks. https://www.autodesk.com/.

27. Trimble Connect. https://connect.trimble.com/.

28. BIM Sync. https://bimsync.com/.

29. BIM Collab. https://www.bimcollab.com/.

30. BIM Spot. https://bimspot.io/.

31. Revizto. https://revizto.com/.

32. Greenwood D, Lockley S, Malsane S, et al. Automated Compliance Checking Using Building Information Models. In: Building and Real Estate Research Conference of the Royal Institution of Chartered Surveyors. London, http://nrl.northumbria.ac.uk/6955 (2010).

33. BuildingSMART. https://www.buildingsmart.org/.

34. Fahad M, Bus N, Fies B, et al. Conformance Checking of IFC Models with the Extensions in the MvdXML Checker. In: ICIW 2018: The Thirteenth International Conference on Internet and Web Applications and Services. 2018.

35. Pauwels P, Van Deursen D, Verstraeten R, et al. A Semantic Rule Checking Environment for Building Performance Checking. Autom Constr 2011; 20: 506-518. 
36. Zhang C, Beetz J, De Vries B. BimSPARQL: Domain-specific functional SPARQL extensions for querying RDF building data. Semant Web 2018; 9: 829-855.

37. Mazairac W, Beetz J. BIMQL - An open query language for building information models. Adv Eng Informatics; 27. Epub ahead of print October 2013. DOI: 10.1016/j.aei.2013.06.001.

38. Lee J-K, Eastman CM, Lee YC. Implementation of a BIM Domain-specific Language for the Building Environment Rule and Analysis. J Intell Robot Syst; 79. Epub ahead of print 21 August 2015. DOI: 10.1007/s10846-014-0117-7.

39. Baumgärtel K, Pirnbaum S, Pruvost H. Automatic BIM filtering using Model View Definitions. In: 33rd CIB W78 Conference 2016. Brisbane, https://www.researchgate.net/publication/310448404 (2016).

40. Werbrouck J, Senthilvel M, Beetz J, et al. Semantic Query Languages for Knowledgebased Web Services in a Construction Context. In: 26th International Workshop on Intelligent Computing in Engineering, http://ceur-ws.org/Vol-2394/ (2018).

41. Werbrouck J, Senthilvel M, Beetz J, et al. A Checking Approach for Distributed Building Data. In: 31st Forum Bauinformatik, https://bim4ren.eu/download/a-checking-approachfor-distributed-building-data/ (2019).

42. Heath T, Bizer C. Linked Data: Evolving the Web into a Global Data Space. Synth Lect Semant Web Theory Technol; 1. Epub ahead of print 9 February 2011. DOI: 10.2200/S00334ED1V01Y201102WBE001.

43. Jiang S, Wu Z, Zhang B, et al. Combined MvdXML and Semantic Technologies for Green Construction Code Checking. Appl Sci; 9. Epub ahead of print 1 April 2019. DOI: 10.3390/app9071463.

44. Fahad M. Conformance Checking of IFC Models via Semantic BIM Reasoner. In: EG-ICE 2018 - Computer Science. 2018.

45. Zahedi A, Petzold F. Interaction with Analysis and Simulation Methods via Minimized Computerreadable BIM-Based Communication Protocol. In: eCAADe + SIGraDi 2019. Porto. Epub ahead of print 2019. DOI: 10.5151/proceedings-ecaadesigradi2019_140.

46. Proving Ground. https://provingground.io/.

47. Bus N, Roxin A, Picinbono G, et al. Towards French Smart Building Code: Compliance Checking Based on Semantic Rules. In: The Twelfth International Conference on Internet and Web Applications and Services, https://thinkmind.org/download.php?articleid=iciw_2017_1_20_20062 (2017).

48. Kiviniemi A. Requirements Management Interface to Building Product Models. VTT Technical Research Centre of Finland, 2005.

49. ISO 19650. https://www.iso.org/standard/68078.html.

50. Beetz J, van Berlo $L$, de Laat $R$, et al. BIMserver. org-An open source IFC model server. In: Proceedings of the 27th CIB W78 Conference on Information Technology in Construction. 2010, pp. 8-undefined. 
51. IFCDoc. https://github.com/buildingSMART/IfCDoc.

52. mvdChecker. https://github.com/opensourceBIM/mvdXMLChecker.

53. van Berlo L, Krijnen T. Using the BIM Collaboration Format in a Server Based Workflow. Procedia Environ Sci 2014; 22: 325-332.

54. Kovacs AT. Integrating Object Genesis Information into BIM database. In: Proceedings of the Young Scientist 2017: 9th International Scientific Conference of Civil Engineering. Kosice, 2017, p. ch. 31.

55. Getuli V, Ventura SM, Capone P, et al. BIM-based Code Checking for Construction Health and Safety. In: Creative Construction Conference 2017. Primosten: Elsevier Ltd, 2017, pp. 454-461.

56. Hjelseth E, Nisbet N. Capturing Normative Constraints by Use of the Semantic Mark-up Rase Methodology. In: CIB W78-W102 2011: International Conference. Sophia Antipolis, 2011, pp. 26-28.

57. The Solid Ecosystem. https://solid.github.io/specification/.

58. Rakic M, Zahedi A, Abualdenien J. Adaptive Minimized BIM-Based Communication and Workflow during Design Phases. In: 31. Forum Bauinformatik: 11. -13. September 2019 in Berlin. Proceedings. Berlin.

59. e-Government Core Vocabularies. https://joinup.ec.europa.eu/solution/e-governmentcore-vocabularies.

60. Dublin Core specifications. https://dublincore.org/specifications/dublin-core/.

61. FOAF Vocabulary Specification 0.99. http://xm/ns.com/foaf/spec/.

62. QUDT. https://github.com/qudt/qudt-public-repo.

63. Succar B. Building information modelling framework: A research and delivery foundation for industry stakeholders. Autom Constr; 18. Epub ahead of print May 2009. DOI: 10.1016/j.autcon.2008.10.003.

64. Morales LG, Orrell T. Data Interoperability: A Practitioner's Guide to Joining up Data in the Development Sector. In: United Nations World Data Forum. 2018.

65. BIMReq ontology. http://demo.dsd.sztaki.hu/bimreq.

66. Shapes Constraint Language (SHACL). W3C Recommendation, https://www.w3.org/TR/shacl/ (2020).

67. Jabi W, Lombardi D, Dounes T. Smart Contracts for Decentralised Building Information Modelling. In: Proceedings of eCAADe/siGRADi conference - volume 1. Porto. Epub ahead of print 2019. DOI: 10.13140/RG.2.2.34686.20809. 